\title{
Biomolecular assembly strategies to develop potential artificial cellulosomes
}

\author{
Geisa AL Gonçalves ${ }^{1}$, Yutaro Mori ${ }^{1}$ and Noriho Kamiya ${ }^{1,2^{*}}$
}

\begin{abstract}
Cellulosic biomass is a sustainable source for fuels and value-added chemicals, and is available in large quantities. One of the key challenges in biomass processing is associated with the establishment of an efficient enzymatic degradation of plant cell wall. A multi-enzymatic complex, cellulosome, was identified as a highly efficient biocatalyst for the hydrolysis of cellulosic biomass in nature. Significant progress has been achieved on cellulosome production and application since its discovery, but there is still a gap for industrial use. Artificial systems are being developed by employing various pairs of proteins and scaffolds with the objective of reconstructing this natural multi-enzymatic complex for sustainable biotechnology application.
\end{abstract}

Keywords: Artificial cellulosome, Biocatalyst, Cellulosome, Lignocellulose, Multi-enzymatic system

\section{Biomass degradation and the multi-enzymatic cellulosome system}

Currently, there is an emergent need for the development of green and sustainable biotechnology. Since global warming and energy crises are examples of serious problems in our society, innovative and renewable substitutes for petroleum are extremely necessary. Lignocellulosic biomass is a sustainable source of natural carbohydrate polymers, which can be converted into fuels and is available in large quantities. Nevertheless, the conversion of lignocellulosic biomass to fermentable sugars still depends on challenges such as the development of highly efficient and cost-effective catalysts. Most of the present raw biomass conversion processes rely on chemical/physical pretreatment and high enzyme loading, resulting in expensive manufacturing and final product. To overcome technical and economical barriers on biomass conversion, innovative solutions are needed.

Multi-enzyme cellulosome systems were described as one of the most efficient natural biocatalyst for degradation of lignocellulosic biomass, and it is a potential alternative for reducing enzyme loading in industrial processes. The synergism among the multiple enzymes and their proximity to the target substrate are essential to the

\footnotetext{
* Correspondence: nori_kamiya@mail.cstm.kyushu-u.ac.jp

'Department of Applied Chemistry, Graduate School of Engineering, Kyushu University, 744, Motooka, Nishi-Ku, Fukuoka, Japan

${ }^{2}$ Center for Future Chemistry, Kyushu University, 744, Motooka, Nishi-Ku, Fukuoka, Japan
}

\section{Artificial cellulosomes for cellulosic biomass hydrolysis}

The general idea of developing an artificial cellulosome was based on the need to create an efficient enzymatic complex system that resembles the cellulolytic ecosystem, and is compatible with industry. The first type of artificial cellulosome proposed was so called designer cellulosome and was suggested by Bayer and co-workers in 1994 [2]. Designer cellulosomes are especially based on the interaction between cohesin and dockerin; and the modification of these key points can potentiate the interaction among enzymes from different species. Furthermore, it is possible to control the specific location of enzyme binding sites. Designer cellulosome was first constructed in 2001 
[3], and since that time significant development and advances have been done. No longer after the construction of the first designer cellulosome, a new model of artificial cellulosome was proposed using staphylococcal protein A, as an artificial scaffold, containing Ig-binding domains, as cohesin modules, and using engineered affibody, as dockerin modules. The protein A cellulosome-like complexes, combined to CBM modules, successfully bound to cellulose surface. However, no cellulolytic enzyme was analyzed in this study [4]. Recently, other types of artificial cellulosomes are being developed, based on different enzyme-scaffold conjugation methods, other than cohesin-dockerin interaction, seeking for alternatives for an efficient and profitable manufacturing process. For example, the use of polystyrene nanoparticles, DNA and streptavidin, have been successfully applied in the creation of artificial cellulosomes (Figure 1).

\section{Artificial cellulosomes based on cohesin-dockerin interaction}

Artificial cellulosome was first proposed based on the tight binding between cohesin and dockerin modules, and it was constructed in vitro, by combination of equimolar amounts of two enzymes and one scaffold [3]. With the creation of designer cellulosomes, the combination of enzymes from different organisms in one single scaffold became possible, as well as the conversion of non-cellulosomal enzymes to cellulosome mode. The flexibility of building designer cellulosomes allowed researchers to probe more deeply into questions about enzyme synergism, such as enzyme position, catalytic domain mobility, and CBM function. For example, a study about cellulosome geometries, comparing different shapes of designer cellulosomes [5], has demonstrated that the intrinsic mobility of catalytic subunits and the use of a single CBM for substrate targeting are important characteristics of the native system that should be taken into consideration on the design of artificial forms. A comprehension of the individual modules of native cellulosomes is crucial for the development of artificial cellulosomes. The high-affinity of cohesin-dockerin and CBM-cellulose interactions are noticeable points in the structural function of cellulosomes. These features have raised interest in many research fields and have led to innovative applications in the industrial biotechnology (reviewed by Hyeon et al. [6]).

Minicellulosomes are smaller and simpler versions of designer cellulosomes, and are also used for enzyme synergy studies, in order to improve plant cell wall degradation. Minicellulosomes display the main advantage of requiring low levels of enzymes, which in turn facilitates their expression in microbial hosts. Recent study by $\mathrm{Xu}$ et al. [7], has

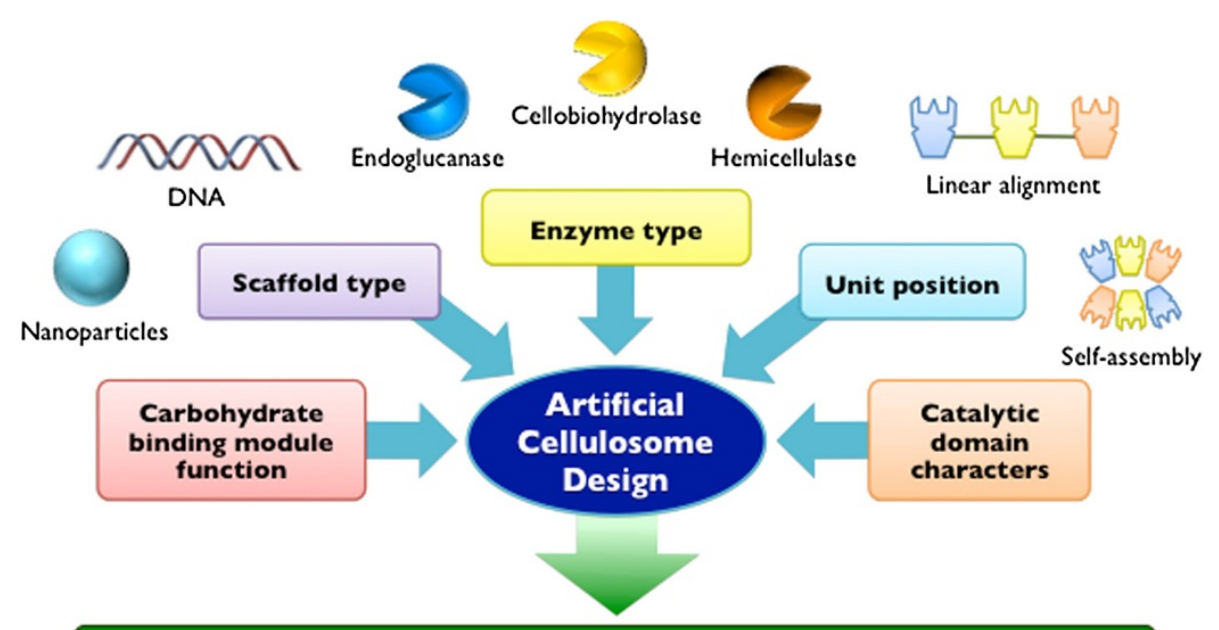

Enzyme synergism for enhancing lignocellulose hydrolysis

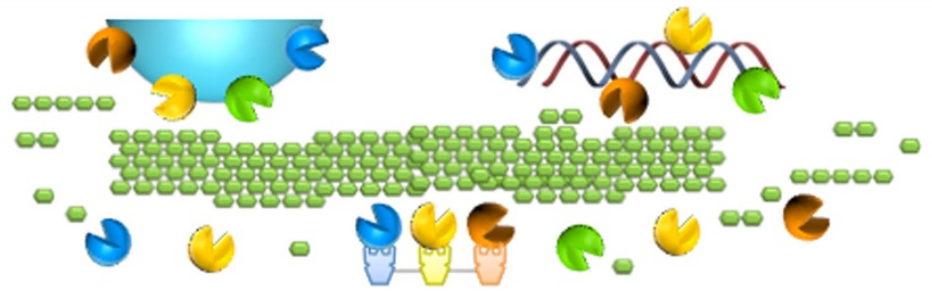

Figure 1 Fabrication of various types of artificial cellulosomes toward the improvement of enzyme synergism for enhancing lignocellulose hydrolysis. 
shown that the application of artificial multicatalytic cellulases on minicellulosomes increased cellulose hydrolysis, due to high intramolecular synergism. Overall, artificial (mini)cellulosomes are still less active than natural cellulosomes on crystalline cellulose and raw substrate. Nevertheless, the reproduction of a full size cellulosome from Clostridium thermocellum has been successfully achieved, with about $20 \%$ less activity than the native one in the hydrolysis of Avicel [8].

The development of artificial designer cellulosomes has boosted the understanding of cellulose hydrolysis in different aspects, but the comprehension of cellulosome structure-function is still not completely clarified. It was only recently, with the combination of advance techniques, such as X-ray crystallographic and cryo-electron microscopic, that high-resolution structural insights of cellulosomes were demonstrated (reviewed by Smith and Bayer [9]). These recent developments in the cellulosome field, related to the plasticity of the cohesin-dockerin interaction and cellulosome assembly, will bring significant impact in the development of novel forms of artificial cellulosomes.

\section{Novel approaches to design artificial cellulosomes}

Artificial cellulosomes, based on cohesin-dockerin interaction, have demonstrated to be efficient over soluble enzymes on the degradation of cellulosic materials. Nevertheless, with the advancement of protein engineering and bioconjugation technology, new clustered enzyme complexes also emerged (Table 1). Different strategies were described to organize multi-enzymes complexes, based on the scaffold material, enzyme type, and conjugation technique. Ring-shaped proteins, carboxysome microcompartment, capsid protein, bacteriophage, RNA and DNA, are examples of synthetic scaffolds for the production of artificial multi-enzyme systems, with potential application for the development of artificial cellulosomes [10].

Nanoscale platforms of different materials are being used as analog to the cellulosomal scaffold. Nanospheres have proven to be a potential scaffold for cellulase immobilization, since they present high specific surface area and minimum diffusional limitation. Using streptavidinbiotin interaction, Kim and co-workers demonstrated the conjugation of catalytic domains and CBM modules onto inorganic nanoparticles [12]. Various ratios of CBMs and catalytic domains were combined using streptavidin or streptavidin-conjugated CdSe nanospheres as cellulosome scaffolds; the increase of CBM modules had positive effect on cellulose hydrolysis (Figure 2). Chemical conjugation technique was also used to immobilize cellulases onto polystyrene nanospheres, the cellulase-nanospherecomplexes were more efficient on crystalline cellulose and recalcitrance wood biomass than on soluble carboxymethyl cellulose [13]. More recently, using metal affinity, a new method of direct conjugation was proposed to cluster cellulases onto nanospheres, $\mathrm{CdSe}-\mathrm{ZnS}$ core-shell quantum dots. As a consequence, more uniform nanoparticles were obtained, nanoparticle size and enzyme proximity were evaluated. In general, enzyme proximity seems to be more crucial in controlling enzyme synergism than particle size [14].

The fabrication of nucleic acid-protein conjugates became very attractive in the last decade, especially in the biomedical area. DNA brings the advantage of being easily manipulated and produced, even in high-length and

Table 1 Design of artificial cellulosome for lignocellulose hydrolysis

\begin{tabular}{|c|c|c|c|c|c|}
\hline Year & Artificial cellulosome & Scaffold-base & Enzyme type & Conjugation technique & Reference \\
\hline 2001 & $\begin{array}{l}\text { First designer } \\
\text { cellulosome }\end{array}$ & $\begin{array}{l}\text { Engineered chimeric } \\
\text { scaffoldin }\end{array}$ & $\begin{array}{l}\text { Clostridium cellulolyticum, CelA, } \\
\text { CelF }\end{array}$ & Cohesin-dockerin interaction & {$[3]$} \\
\hline 2003 & $\begin{array}{l}\text { Protein A- CBM - } \\
\text { enzyme conjugates }\end{array}$ & Staphylococcal protein A & $\begin{array}{l}\text { EGFP, Fusarium solani pisi } \\
\text { lipase cutinase }\end{array}$ & IgG-affibody interaction & {$[4]$} \\
\hline 2009 & Rosettazyme & $\begin{array}{l}\text { Group II Chaperonin } \\
\text { (Rosettazomes) }\end{array}$ & $\begin{array}{l}\text { Clostridium thermocellum, } \\
\text { Cel9B, Cel9K, Cel9R, Cel48S }\end{array}$ & Cohesin-dockerin interaction & {$[11]$} \\
\hline 2011 & Nanocluster & $\begin{array}{l}\text { Streptavidin-immobilized } \\
\text { inorganic nanoparticles }\end{array}$ & Aspergillus niger, EgIA & Avidin-biotin interaction & {$[12]$} \\
\hline 2012 & Nanocluster & Polystyrene nanosphere & Trichoderma viride cellulase & $\begin{array}{l}\text { EDC and Sulfo-NHS coupling } \\
\text { chemistry }\end{array}$ & {$[13]$} \\
\hline 2013 & Nanocluster & $\begin{array}{l}\text { CdSe-ZnS core-shell } \\
\text { quantum dots (QDs) }\end{array}$ & $\begin{array}{l}\text { Clostridium thermocellum CelA, } \\
\text { Clostridium cellulolyticum CelE }\end{array}$ & $\begin{array}{l}\text { Metal affinity between core-shell } \\
\text { QDs and polyhistidine tag }\end{array}$ & {$[14]$} \\
\hline 2013 & $\begin{array}{l}\text { Cellulase-ankyrin } \\
\text { fusions }\end{array}$ & Ankyrin & $\begin{array}{l}\text { Clostridium thermocellum CelA, } \\
\text { Thermotoga maritima, Cel12A }\end{array}$ & Protein fusion & {$[15]$} \\
\hline 2013 & $\begin{array}{l}\text { DNA-cellulase covalent } \\
\text { conjugates }\end{array}$ & Double strand DNA & Thermobifida fusca, Cel5A & MTG mediated cross-linking & {$[16]$} \\
\hline 2014 & $\begin{array}{l}\text { DNA-cellulase non- } \\
\text { covalent conjugates }\end{array}$ & Double strand DNA & Clostridium thermocellum, CelA & $\begin{array}{l}\text { Zinc-finger protein guided } \\
\text { assembly }\end{array}$ & {$[17]$} \\
\hline
\end{tabular}




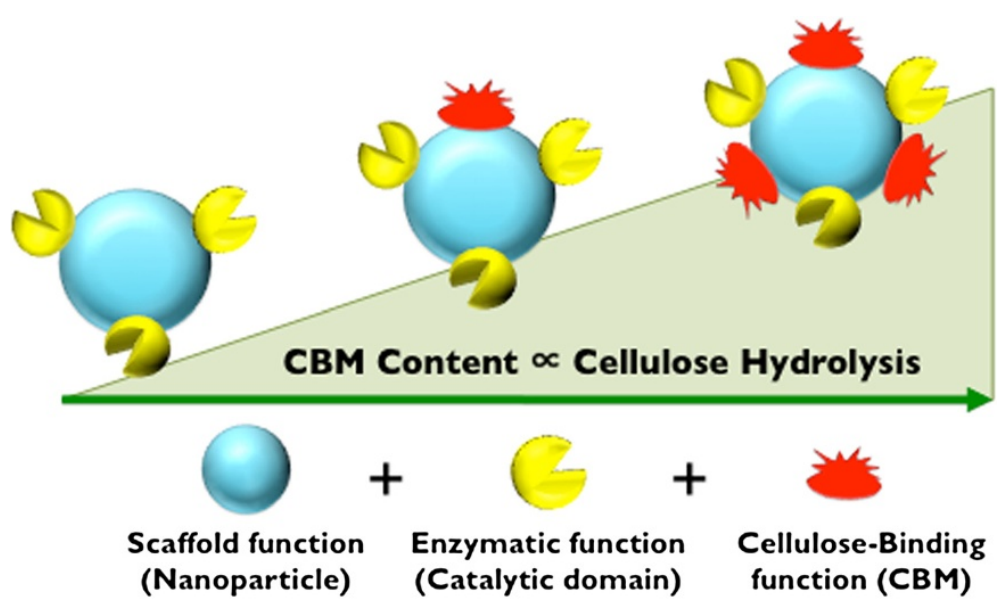

Figure 2 The importance of CBM module on cellulose hydrolysis in the case of nano-cluster artificial cellulosome design.

complex forms, it has great mechanical rigidity and high physicochemical stability. The use of DNA to produce a potent artificial cellulosome was demonstrated for the first time [16]. To prepare DNA-cellulase conjugates, a protein crosslinking enzyme, microbial transglutaminase, has been used. We found that there may be an optimal density of the conjugated enzyme, Cel5A endoglucanase from Thermobifida fusca, on the DNA scaffold. Enhancement of 5.7-fold in enzymatic saccharification was observed when comparing to free enzyme, in the hydrolysis of Avicel in the presence of free endoglucanase and $\beta$-glucosidase. No later, a different preparation form of DNA-enzyme conjugate was proposed using zinc-finger proteins, based on the ability of these proteins to recognize specific sequences of double-stranded DNA. The combination of catalytic domain and CBM modules were also tested in DNA scaffolds; 1.7-fold enhancement on cellulose hydrolysis was observed with the conjugation of one CelA and one CBM module onto DNA scaffold. The addition of an extra CBM module on the artificial DNA cellulosome increased only $15 \%$ in reducing sugar production [17].

Other synthetic cellulosomes were created, associating protein engineering and cohesin-dockerin interaction, as for example, the multi-enzyme rosettazyme [11]. A synthetic cellulosome was constructed based on the self-assembling protein complex, rosettasome, containing cohesin, combined with maximum four $C$. thermocellum cellulases. Interestingly, rosettazyme artificial cellulosome proved to be more efficient when combining two or more enzymes in the scaffold. The addition of a specific CBM module was also analyzed in the rosettazyme, but no improvement was observed in the cellulase activity. Recently, a study has demosntrated the use of ankyrin scaffold combined with endocellulase catalytic domains, as a potent strategy to fabricate artificial cellulosomes. Ankyrin protein proved to be a stable scaffold, increasing cellulase thermostability and activity, especially because the cellulase domains were internal to the scaffolding protein [15].

Toward practical application of cellulosomes to industry, the integration of recombinant cellulosomes into natural systems has been demonstrated. To accomplish a consolidate process for biofuel production, where cellulase production, cellulose hydrolysis and sugar fermentation occured in one step, the display of cellulosomes on yeast surface has been developed [18]. Natural cellulosomes are found on the cell wall of microorganisms, and this feature can be advantageous for saccharification process, once it enhances enzyme local concentration, and facilitates the consumption of cellobiose and cellodextrin, decreasing product inhibition [19]. A bioenergetic model of cellodextrin consumption for the C. thermocellum was previously described, demonstrating that assimilation of high lengths of glucose chain are usually associated with ATP saving [20]. Nevertheless, enzyme-microbe synergy is not explained only by the removal of inhibitory products, this complex can also affect the properties of the substrate in the region between cellulose and the adhered cellulolytic microorganism [21]. A mini-cellulosome displayed at $B$. subtilis cell surface, was more active than the free version of the same cellulosome on low-accessibility Avicel or high-acessibility regenerated amorphous celullose [22]. Furthermore, to enhance lignocellulosic biomass degradation other strategies focused on the degradation of hemicellulose have been shown, such as the creation of xylanase-containing designer cellulosomes [23], artifiticial xylanosomes [24] or minihemicellulosomes [25].

\section{Competing interests}

The authors declare that they have no competing interests.

\section{Authors' contributions}

Wrote the paper: GALG and NK. Designed the figures: YM and NK. All authors read and approved the final manuscript. 


\section{Acknowledgment}

This research was supported by the Advanced Low Carbon Technology Research and Development Program (ALCA) from the Japan Science and Technology Agency (JST).

Received: 4 April 2014 Accepted: 23 September 2014

Published online: 07 October 2014

\section{References}

1. Fontes CM, Gilbert HJ: Cellulosomes: highly efficient nanomachines designed to deconstruct plant cell wall complex carbohydrates. Annu Rev Biochem 2010, 79:655-681.

2. Bayer EA, Morag E, Lamed R: The cellulosome - a treasuretrove for biotechnology. TIBTECH 1994, 12:379-386.

3. Fierobe HP, Mechaly A, Tardif C, Belaich A, Lamed R, Shoham Y, Belaich JP, Bayer EA: Design and production of active cellulosome chimeras. Selective incorporation of dockerin-containing enzymes into defined functional complexes. J Biol Chem 2001, 276:21257-21261.

4. Eklund M, Sandstrom K, Teeri TT, Nygren PA: Site-specific and reversible anchoring of active proteins onto cellulose using a cellulosome-like complex. J Biotechnol 2004, 109:277-286.

5. Mingardon F, Chanal A, Tardif C, Bayer EA, Fierobe HP: Exploration of new geometries in cellulosome-like chimeras. App/ Environ Microbiol 2007, 73:7138-7149.

6. Hyeon JE, Jeon SD, Han SO: Cellulosome-based, Clostridium-derived multi-functional enzyme complexes for advanced biotechnology tool development: advances and applications. Biotechnol Adv 2013, 31:936-944

7. Xu Q, Ding SY, Brunecky R, Bomble YJ, Himmel ME, Baker JO: Improving activity of minicellulosomes by integration of intra- and intermolecular synergies. Biotechnol Biofuels 2013, 6(126):1-10.

8. Krauss J, Zverlov W, Schwarz WH: In vitro reconstitution of the complete Clostridium thermocellum cellulosome and synergistic activity on crystalline cellulose. Appl Environ Microbiol 2012, 78:4301-4307.

9. Smith SP, Bayer EA: Insights into cellulosome assembly and dynamics: from dissection to reconstruction of the supramolecular enzyme complex. Curr Opin Struct Biol 2013, 23:686-694.

10. Chen R, Chen Q, Kim H, Siu K, Sun Q, Tsai SL, Chen W: Biomolecular scaffolds for enhanced signaling and catalytic efficiency. Curr Opin Biotechnol 2014, 28:59-68.

11. Mitsuzawa S, Kagawa H, Li Y, Chan SL, Paavola CD, Trent JD: The rosettazyme: a synthetic cellulosome. J Biotechnol 2009, 143:139-144.

12. Kim DM, Umetsu M, Takai K, Matsuyama T, Ishida N, Takahashi H, Asano R, Kumagai I: Enhancement of cellulolytic enzyme activity by clustering cellulose binding domains on nanoscaffolds. Small 2011, 7:656-664.

13. Blanchette C, Lacayo Cl, Fischer NO, Hwang M, Thelen MP: Enhanced cellulose degradation using cellulase-nanosphere complexes. PLOS One 2012, 7(8):e42116.

14. Tsai SL, Park M, Chen W: Size-modulated synergy of cellulase clustering for enhanced cellulose hydrolysis. Biotechnol J 2013, 8:257-261.

15. Cunha ES, Hatem CL, Barrick D: Insertion of endocellulase catalytic domains into thermostable consensus ankyrin scaffolds: effects on stability and cellulolytic activity. Appl Environ Microbiol 2013, 79:6684-6696.

16. Mori Y, Ozasa S, Kitaoka M, Noda S, Tanaka T, Ichinose H, Kamiya N: Aligning an endoglucanase Cel5A from Thermobifida fusca on a DNA scaffold: potent design of an artificial cellulosome. Chem Commun (Camb) 2013, 49:6971-6973.

17. Sun Q, Madan B, Tsai SL, DeLisa MP, Chen W: Creation of artificial cellulosomes on DNA scaffolds by zinc finger protein-guided assembly for efficient cellulose hydrolysis. Chem Commun (Camb) 2014, 50:1423-1425

18. Tsai SL, DaSilva NA, Chen W: Functional display of complex cellulosomes on the yeast surface via adaptive assembly. ACS Synth Biol 2013, 2:14-21.

19. Lynd LR, Weimer PJ, Van ZyI WH, Pretorius IS: Microbial cellulose utilization: fundamentals and biotechnology. Microbiol Mol Biol Rev 2002, 66:506-577.

20. Zhang YH, Lynd LR: Cellulose utilization by Clostridium thermocellum bioenergetics and hydrolysis product assimilation. Proc Natl Acad SCi U S A 2005, 102:7321-7325.
21. Lu Y, Zhang $Y H$, Lynd LR: Enzyme-microbe synergy during cellulose hydrolysis by Clostridium thermocellum. Proc Natl Acad Sci U S A 2006, 103:16165-16169.

22. You C, Zhang XZ, Sathitsuksanoh N, Lynd LR, Zhang YH: Enhanced microbial utilization of recalcitrant cellulose by an ex vivo cellulosome-microbe complex. Appl Environ Microbio/ 2012, 78:1437-1444.

23. Morais S, Barak Y, Hadar Y, Wilson DB, Shoham Y, Lamed R, Bayer EA: Assembly of xylanases into designer cellulosomes promotes efficient hydrolysis of the xylan component of a natural recalcitrant cellulosic substrate. MBio 2011, 2(6):e00233-e00311.

24. McClendon SD, Mao Z, Shin HD, Wagschal K, Chen RR: Designer xylanosomes: protein nanostructures for enhanced xylan hydrolysis. Appl Biochem Biotechnol 2012, 167:395-411.

25. Sun J, Wen F, Si T, Xu JH, Zhao H: Direct conversion of xylan to ethanol by recombinant Saccharomyces cerevisiae strains displaying an engineered minihemicellulosome. App/ Environ Microbiol 2012, 78:3837-3845.

doi:10.1186/s40508-014-0019-9

Cite this article as: Gonçalves et al:: Biomolecular assembly strategies to develop potential artificial cellulosomes. Sustainable Chemical Processes 2014 2:19.

Publish with ChemistryCentral and every
scientist can read your work free of charge
"Open access provides opportunities to our
colleagues in other parts of the globe, by allowing
anyone to view the content free of charge."
W. Jeffery Hurst, The Hershey Company.
- available free of charge to the entire scientific community
- cited in PubMed and archived on PubMed Central
- yours - you keep the copyright
Submit your manuscript here:
http://www.chemistrycentral.com/manuscript/

